\title{
Locuras de Europa
}

«... la escogió (a la Casa de Austria) Dios en la ley de gracia, assi como la de Abraham en la escrita para llamarse Dios de Austria, Dios de

Rodolfo, de Felipe, y de Fernandow

Baltasar Gracián. El político Don Fernando el Católico.

\author{
JULIÁN VIEJO YHARRASSARRY *
}

La conclusión de los tratados de Münster y Osnabrück que conjuntamente fueron conocidos como Paz de Westfalia no debió ser especialmente favorable para las pretensiones de orden dinástico en las que habitualmente se venía moviendo la Casa de Austria. Particularmente, la "Separación» ${ }^{1}$ que los mismos acabaron por imponer entre las dos ramas ya fue interpretada contemporáneamente como un duro golpe a las aspiraciones de dominio universal que se consideraban inherentes a la propia dinastía habsbúrgica ${ }^{2}$. En efecto, en Westfalia acabó por configurarse un proyecto de solución al problema imperial y de dimensión europea centrado en la defensa de un orden de "libertades" que se pretendía permanente y que intentaba reducir las posibilidades de éxito, salvo in-

* Universidad Autónoma de Madrid.

Vid. con detalle acerca de la "Trennung», DickmanN, F. Der Wesfälische Frieden. Münster (1959), 1985, págs. 260 y ss. Asimismo, REPGEN, K., *Ferdinand III» in Schindling/Ziegler (Edts), Die Kaiser der Neuzeit, 1519-1918. Munich 1990, págs. 159 y ss.

2 Vid. al respecto la relación de Alvise Contarini, mediador de la Paz de Westfalia por parte de la República de Venecia, de 26 de septiembre de 1650 in Die Relationen der Botschafter Venedigs über Deutschland und Österreich in sebzehnten Jahrhundert. Fontes Rerum Austriacarum. Österreischiche Geschichts-Quellen. Hersgb. v. der Historischen Commision der Kaiserlichen Akademie der Wissenschaften in Wien, Abt. 2, Band XXV, FIEDLER, J. (Edt.), Tomo I, Kaiser Mathias bis K. Ferdinand III. Viena 1866, págs. 293 y ss. Los embajadores venecianos no dejarán de reiterar la doble dimensión de nuestro asunto. Por un lado, la separación de intereses entre la rama austriaca y la hispana y la significación de la "Trennung» para ello, y por otro, como veremos, la continuidad marcada ahora sobre todo desde Madrid de la pretensión de dominio y de reunión de la casa. Vid, así, la relación, ya avanzado en el tiempo y en situación de "crisis" sucesoria en Viena, de Girolamo Giustinianni de 25 de febrero de 1654, lbidem, págs. 385 y ss. 
tencionadas perversiones del propio proyecto y con mecanismos de defensa frente a ellas, de un diseño de imposición de un orden europeo fundado en una concepción de "Pax et Imperium" ${ }^{3}$, que mejor pudiera haber representado la propia casa de Austria y que ahora pudiera sustanciarse, casi en exclusiva, desde el lado de la Monarquía Católica ${ }^{4}$. Aspiraciones a una Monarquía Universal ${ }^{5}$ ahora parecía que ya no cabían. Pero había además otra cara de la moneda, también de incidencia directa sobre tales presupuestos de imposición. Los acuerdos de 1648 constituyeron no menos una salida, por vez primera universal y ciertamente estable, de superación del enfrentamiento confesional; una paz política en materia de religión; una solución supraconfesional al enfrentamiento religioso ${ }^{6}$. Desde el lado de la Monarquía Catćlica hubo de responderse. $Y$, a nuestro entender, la reacción se produjo más en la dirección de afirmar los supuestos confesionales ${ }^{7}$ y los conceptos de dominio y dinásticos con ellos incardinados, y ahora especialmente conjuntados, que en la de una aceptación del orden postwestfaliano. Al fin y al cabo también se nos había recordado que pese a la "Separación» el disegno permanecía. Se trataba de: «... riunir in una le due case d'Austria cioè di Germania e Spagna, macchina che sarà difficile da maneggiarsi, e che propala il disegno di quei vasti concetti di dominio, che nè reiterate disgrazie, nè l'instabilità di accidenti, nè la ribellione de' propii sudditi ha potuto sradicare nel superbo cuor dei spagnuoli»" ${ }^{8}$.

3 Straub, E., Pax et Imperium. Spaniens Kampf um seine Fridensordnung in Europa zwischen 1617 und 1635. Paderborn 1980, págs. 11 y ss.

4 Vid. para esta interpretación de la Paz de Westfalia, Barudio, G., Der Teutsche Krieg, 16181648. Frankfurt a. Main 1985, págs. 573 y ss. Y para la continuidad de tales supuestos de paz y libertades, Schindling, A., Die Anfänge des Immerwährenden Reichtags zu Regensburg. Ständvertretung und Staatskunst nach dem Westfälischen Frieden. Maguncia 1991, esp. págs. 46 y ss. Sobre la concepción de Westfalia como "proyecto", HAUG-MORITZ, G., «Kaisertum und Parität. Reichspolitik und Konfessionen nach dem Westfälischen Frieden", Zeitschrift für Historische Forschung, 19, 1992, 4, págs. 445 y ss.

5 Sobre el "tópico" BosBaCH, F., Monarchia Universalis. Ein politischer Leitbegriff der fruhën Neuzeit. Göttingen 1988, passim.

6 Vid. por todos, HECKEL, M., Deutschland im konfessionellen Zeitalter. Gottingen 1983, págs. 181 y ss.

7 Para los conceptos de Konfession, Konfessionsbildung, Konfessionalisierung, y otros relacionados y de utilización hasta ahora básicamente alemana, vid. ZEEDEN. E.W., Konfessionsbildung. Studien zur Reformation, Gegenreformation und katholischen Reform. Sttutgart 1985. Asimismo, Schilling, H., Religion, Political Culture and the Emergence of the Early Modern So. ciety. Essays in German and Dutch History. N. York 1989, passim.

a "Relazione di Spagna di Girolamo Giustinian ambasciatore a Filippo IV dall'anno 1643 al 1649", in BAROzZI, N. y BERCHET, G. (Edts.), relazioni degli Stati Europei lette al Senato dagli Ambasciatori Veneti nel secolo decimoseftimo. Serie I -Spagna-Vol. II. Venecia 1860, pág. 141. 
Con el Congreso de Paces ya en marcha Diego Saavedra Fajardo, quien siempre se había caracterizado por una buena dosis de explicitación de sus planteamientos en materia confesional ${ }^{9}$, podía concretar posiciones de paz que remitían a una estricta vinculación entre Casa de Austria, Imperio y Catolicidad:

\begin{abstract}
“Ninguna cosa me movió más a confusión que Alemania, viendo que era esclava de las naciones la que por imperio del mundo, que en ella resplandece, debía ser señora de todas... que tenga por protección lo que es tiranía y por libertad lo que es servidumbre;... Que, pudiendo con la unión y concordia aspirar al dominio universal, se rinda por su división a sus enemigos; que piense obligallos con separarse de la cabeza que la gobierna y con abandonar la amistad y confederación de los que son interesados en su misma conservación y comunes en la causa; que a título de religión, la pierdan; y que hagan consejeros de la paz a los que hacen la guerra" ${ }^{10}$.
\end{abstract}

«Locuras de Europa» eran éstas. Expresión de un proyecto que sólo de "locuras" se podía calificar cuando se analizaba bajo el prisma de una percepción confesional del mundo. El concurso de posiciones ciertamente explícitas de rechazo también permitía asentar reacciones ${ }^{11}$. Al fin y al cabo, ya se no indicaba que «las batallas en que oy está empeñada España son propiamente de Dios, porque son por causa de la Religión". Lo que en estos momentos se jugaba en Europa, también se nos decía, no era otra cosa que la "conservación de la Monarquía de Jesu Christo" lo que en esencia depende de que "el sacro Imperio no salga de la Casa de Austria» '2. Interesan las fechas. Que esto se dijera en 1647 ya era

- Para posicionamiento anterior de nuestro autor, véase ALDEA VAOUERo, Q., España y Europa en el siglo XVII. Correspondencia de Saavedra y Fajardo, (Tomo I que cubre los años 163133. Madrid 1986 y Tomo II, para 1634. Madrid 1991).

10 SaAvedra y Fajardo, D. de, "Locuras de Europa. Diálogo entre Mercurio y Luciano," en Obras Completas, González Palencia, A. (Edt.) Madrid 1946, pág. 1.199. La obra ya estaba probablemente compuesta en 1643, (Cfr. DowLING, J. C., Edt. República Literaria. Madrid 1967. pág. 17), aunque al parecer no alcanzó publicación hasta 1748 (González PALENCIA, Obras, cit., pág. 1.195).

Vid. PONS DE CASTELvi, F., Gustavo Adolfo de Suezia, venzedor y venzido en Alemania. Madrid 1648. La dedicatoria del autor lleva fecha de 20 de diciembre de 1647.

12 Enriquez, F., Conservación de Monarquías, religiosa y política. Primera y segunda parte. A la Católica, Sacra, y Real Magestad de Felipe Quarto el Grande nuestro Señor. Madrid 1648. La dedicatoria del autor lleva fecha de 22 de marzo de 1647. Recoge las citas ArCO y GaraY, R. del, La ldea de Imperio en la Política y en la Literatura españolas. Madrid 1944, págs 252 y ss. donde además se ofrece noticia de planteamientos contemporáneos en el mismo sentido. 
ciertamente indicativo. Liberado quizás de la relativa prudencia a la que le obligaba la labor de plenipotenciario, el propio Saavedra también concretaba posiciones en su Corona Gótica, «thèse de circonstance» en cierta manera dada la intención de acercamiento diplomático hacia los suecos, pero que no dejaba de presentar sustancia de más alto alcance.

Era en 1646, era en Münster ${ }^{13}$. Sobre ella habremos de volver, pero interesa también retener ahora la reiteración de supuestos. Ya lo señalaba Ataulfo a sus soldados:

"Y cuando esta desconfianza y el apetito de dominar (poderoso en vuestros corazones) os obligue a mayor monarquía, de ninguna parte mejor que desde España podéis aspirar al dominio universal»

Pero antes ya se habría concretado que "los españoles conservaban la religión católica" y que.. "sobre tan grandes columnas de la Iglesia Universal se fundó la de España como quien en tiempos futuros había de mantener y propagar la fe en la mayor parte del mundo ${ }^{14}$, sin que faltasen referencias desde el inicio al cumplimiento de profecías.

«Todos somos godos» informaba el Conde de Peñaranda que le referían los plenipotenciarios suecos ${ }^{15}$. Pero al parecer de forma distinta entre unos y otros ${ }^{16}$. La visión confesional marcaba la diferencia. $Y$ era

13 SaAvedra y Fajardo, D. de, Corona Gótica, Castellana y Austriaca, políticamente ilustrada. La dedicatoria lleva fecha de 8 de septiembre de 1645. El propio Saavedra, como es sabido informaba en carta de 3 de mayo de 1644 que tenía pendiente de dar ala última mano" a un libro titulado:“Corona Austriaca, Gótica y Castellana, en que políticamente y para instrucción del Príncipe, nuestro Señor, escribo las vidas de los Reyes Godos y de los de Asturias, León y Castilla," en Codoin. Tomo 82, pág. 41 y que reproduce González Palencia en Obras, cit. Dado que el mismo autor nos informa que la elaboración se produjo en Münster, donde ya se encontraba en 20 de noviembre de 1643, entre estas fechas debió de llevar a cabo la composición más inicial de la obra. Vid. para los datos, Fraga IRIBARNe, M., Diego de Saavedra y Fajardo y la diplomacia de su época. Madrid 1955, págs. 401 y ss. y 544 y ss. La primera edición de la Corona es de 1646, en Münster. La edición de la $B A E$, ha suprimido, tranquilamente, todas las notas del propio Saavedra.

14 Corona Gótica, ed. cit. Cap. II, pág. 735. Para las referencias proféticas, ibidem, pág. 724.

15 “Peñaranda a su Majestad", carta de 9 de diciembre de 1645, Codoin, t. 82, pág. 235.

16 A efectos comparativos y con perspectiva europea, BARUDIO, G., «lm Zeichen des Goticismus-Sweden zur Beginn der Neuzeit» in Fetscher, I y Munkler, H. (Edts.), Pipers Handbuch der Politsichen Ideen. Band 3, Neuzeit: Von der Konfessionskriegen bis zur Aufklärung. Munich 1985, págs. 179 y ss. y esp. 181-182. Interesante, y con dimensión europea, JOHANNESSON, K., The Renaissance of the Goths in Sixteenth Century Sweden. Johannes and Olaus Magnus, Politicians and Historians. Berkley (1982), 1991. esp. págs. 67 y ss. Planteamiento más medieval aunque para ámbito hispano, MESSMER, H. Hispania-Idee und Gotenmithos. Zu den Voraussetzungen des traditionellen vaterländischen Geschichtsbildes im spanischen Mittelalter. Zurich 1960 , págs. 9 y ss. 
cuestión inicial esta de la oposición a «herejes» que de tales presupuestos pudiera derivarse. Era sin duda lo más visible, lo más manifiesto. De herejes se trataba. $Y$ se trataba en abundancia. Al fin y al cabo ya nos lo había señalado Quevedo: "Y hase de advertir que la primera batalla que fue la de los ángeles, fue contra herejes" "17. Pero subyacian preocupaciones de radio mayor. En escena irrumpian «hombres meramente politicos» o "políticos» tout court que parecían a la postre constituir el verdadero blanco de ataque. Y tanto más, cuanto que podía por esta vía deslizarse la presencia de "católicos» que bajo estos parámetros de conducta "política» conformasen núcleo radical de oposición a la «verdad» católica. Ya se trataba de herejes y de algo más que de herejes, sin dejar de ser lo primero. $O$, tal vez mejor, de la conjunción de ambas condiciones a un tiempo. Ciertamente se estaba en el seno de una tradición con momento fundante a finales de la anterior centuria, pero cuyos contenidos también debieron de concretarse al hilo de la propia dinámica confesional. Los tiempos parecian ahora imponer dosis de mayor explicitación. Discursos en principio más distantes podían también contener los argumentos. Incluso los encontrábamos en Indias. Solórzano vertía en estos momentos al castellano su De Indiarum lure. Junto a Lutero y «otros herejes» aparecian Maquiavelo y Bodino, también catalogados de herejes, e incluso se habilitaba un espacio para la irrupción discreta en los mismos términos de "Grotius" ${ }^{18}$.

Nos adentrábamos ahora más en una batalla de «razones» diversas. Se trataba en sustancia de resucitar presupuestos que no eran nuevos. De recoger tradiciones. Pero ya nos interesa el momento preciso y la dinámica de la que no se sale cuando no faltan experiencias de otra índole que pudieran figurar construcciones o proyectos distintos, y además de radio europeo. Ciertamente, de manera clara se nos había advertido del componente religioso que encerraban todas las guerras presentes. Pero

17 Quevedo y VIllegas, F., Política de Dios, Gobierno de Cristo, Segunda Parte, Cap. XXIII, secc. II, pág. 305 de la ed. de Crosby, J.O. (Madrid, 1966), cuyo prólogo informa de las fechas de redacción y edición.

18 Solórzano y Pereyra, J. de, Política Indiana Tomo I, Cap. VIII, pág. 84 de la edición de la BAE. Madrid1972, que recoge la publicación de 1930 llevada a cabo por la Compañía Iberoamericana de Publicaciones, que es a su vez edición del siglo XVIII, con corrección y enmiendas de Francisco Ramiro Valenzuela. El mismo Solórzano se encargaría de realizar esta versión castellana de su De Indiarum lure, obrando más que mera traducción. La versión parecia concluida en 26 de mayo de 1646, según fecha el mismo autor en el Lib. VI, Cap. XVII, que es el último de la obra. La portada del ejemplar de la Biblioteca Nacional de Madrid catalogado por $\mathrm{R} / 34077$, lleva fecha de 1647, mientras que en el interior del mismo ejemplar aparece 1648 (en romanos), que debió de ser la fecha definitiva de edición por cuanto la Tassa del Consejo lleva fecha de 13 de junio de 1648 , que es la más reciente. 
el asunto no era sólo de obviedades, lo era también de mayor calado. El que se deriva del hecho diferencial de que:

"Otros Monarcas toman la religión por estado de la conservación de sus monarquías; pero el católico haze de la monarquía estado del aumento de la religión» ${ }^{19}$.

El argumento era de negación de una razón de estado que se quería afirmar por encima de la razón propia de religión, por encima de una razón católica ${ }^{20}$. Blázquez Mayoralgo podía empezar por ofrecer una Perfecta razón de Estado ${ }^{21}$, que se quería contra, precisamente, «políticos atheistas". Y es que de lo que se trataba era de comprender que lo que éstos introducen por ciencia para "gobernar con tiranía" era lo que los sagrados doctores hazen ley para regir con prudencia" 0 , más esencialmente, que "ésta no se deduce de los caminos violentos (no en vano había ya citado a Maquiavelo) ${ }^{22}$, que ellos atribuyen a la conservación, sino de las disposiciones que se encaminan a lo Catholico". Se estaban explicitando los fundamentos de toda una Weltanschauung. $Y$ ahí radicaba el nudo de la cuestión.

19 Enríuez, F. Conservación de Monarquías, cit. Parte Primera, Cap. XIII, fol. 16.

20 Vid. Clavero, B., Razón de estado, razón de individuo, razón de Historia. Madrid 1991, págs. 15 y ss. Del mismo, Antidora. Antropología Católica de la Edad Moderna. Milán 1991, passim. Asimismo, con atención a nuestro problema y reconstrucción histórica imprescindible, Fernández Albaladejo, P., Fragmentos de Monarquía. Trabajos de historia politica. Madrid 1992. passim. Con carácter de información de una tradición, cfr. STOLLEIS, M. "Arcana Imperii und Ratio Status. Bemerkungen zur politischen Theorie des frühen 17. Jahrhunderts" ahora en su Staat und Staatsräson in der frühen Neuzeit. Studien zur Geschichte des öffentlichen Rechts. Frankfurt a. Main 1990, págs. 37 y ss., con adición de literatura de ámbito hispano en pág. 61. Asimismo, SchNuR, R. (Edt.), Staatsräson. Studien zur Geschichte eines politischen Begriffs. Berlin 1975 (que son actas de Coloquio Internacional celebrado en Tubinga en 1974). E interesaudo directamente, Pocock, J. G. A., «Reconstructing the Traditions: Quentin Skinner's Historians' History of Political Thought", en Canadian Journal of Political and Social Theory, Vol. 3, 1979, págs. 95 y ss. BIRELEY, R., The Counter-Reformation Prince. Anti Machiavellianism or Catholic Statecraft in Early Modern Europe. Chapel Hill 1990, esp. 188 y ss. Reciente y con poca atención al problema confesional, VIROLI, M., From Politics to reason of state. The adquisition and transformation of the language of politics, 1250-1600. Cambridge 1992, págs. 3 y ss. También reciente y ahora sí con atención a la cuestión confesional, Tuck, R., Philosophy and Government, 1572-1651. Cambridge 1993, esp. págs. 31 y ss. y 131 y ss. Util siempre, FERNÁNDEZ Santamaria, J. A., Razón de Estado y política en el pensamiento español del Barroco (1595-1640). Madrid 1986, passim.

21 Blázouez Mayoralgo, J., Perfecta razón de estado, deducida de los hechos de el Señor Don Fernando el Catholico, Quinto de este nombre en Castilla y Segundo en Aragón, contra los políticos atheistas. México 1646. La censura más antigua lleva fecha de julio de 1645.

22 Y lo citaba a la cabeza de los políticos:

“... contra el error de los Políticos, cuyos preceptos bárbaros son (y principalmente de su capitán Machiavello) que todas las cosas penden del hado de la Fortuna", interesando, por lo que veremos también esta última parte. Las citas son todas de la Dedicatoria del autor al Rey. 
La Corona Gótica contribuía a afirmar por vías no distantes los mismos supuestos de fondo. $Y$ como ya advertimos, se trataba, desde Münster, de arrojar luz sobre los "derechos legítimos en que se fundó el reino y Monarquía de España" a partir de la "verdad de la historia» ${ }^{23}$. ¿Pero en qué acababa concretándose este proyecto que se nos decía histórico? Ciertamente, menos en historia que en religión. La cuestión que al fin acaba por preocupar es la de la verificación del componente católico de la Monarquía hispana. Era esa la resultante de la inquisición de la relación entre presente y pasado que pudiera generar la operación. $Y$ lo era en términos de derivación netamente confesional:

"Considero Recaredo - se nos decía- como prudente que las inquietudes de su Reino y las conjuras contra su persona procedían de no estar bien firme en los ánimos de sus vasallos la religión católica» ${ }^{24}$.

Y ello cobraba especial significación por cuanto ya acontecía tras enfrentamientos fraternos y no menos religiosos ${ }^{25}$. La solución se encontró en la convocatoria de un Concilio y en él el rey se encargó de levantar «la primer (sic) piedra fundamental» ${ }^{26}$ en la religión católica. $Y$ se comenzaba por donde se debía: "Confesemos". Así, el cuidado de los reyes, se indicaba, «se ha de extender a que con fundamento y scientia se entienda la verdad". De qué verdad se trataba ya podrá imaginarse. No pudo Saavedra, como es sobradamente conocido, concluir el proyecto. Pero halló continuador, como también es sabido. El inicio de la continuación significa. Enmarca resultados. La "pérdida de España", nos recordaba

23 SaAvedra, Corona Gótica, “Al Lector", págs. 707 y ss. de la ed. de González Palencia.

24 Corona Gótica, Cap. XV, pág. 890 de la ed. cit.

${ }_{25}$ Aquellos que habían enfrentado a Leovigildo con su hijo Hermenegildo por materia de religión. Leovigildo, que era "muy astuto como suelen ser los herejes" ya había preparado sus tropas "como conducidas para guerra de religión» cuando intentó recomponer la situación. Al efecto señalaba a su hijo que:

"La razón de estado de tus mayores ha sido siempre unir los ánimos de los vasallos con el vínculo de una sola religión, y tu fomentas y te haces cabeza de la católica" (Ibidem, Cap. XIV, pág. 867).

La respuesta no tiene desperdicio:

"Reconozco de ti, oh padre y señor, el ser de naturaleza y de fortuna; pero no el del alma que recibí de Dios; y cuando las obligaciones naturales se oponen a las del Criador precepto es divino que el hijo se aparte del padre y el padre del hijo. Y así, no la ambición de la corona temporal, sino el deseo de la eterna me ha hecho cabeza de los católicos, despreciando los peligros internos y externos y las máximas politicas de mis progenitores, porque no se ha de gobernar la religión por la razón de estado, sino la razón de estado por la religión" (ibidem, pág. 868).

Las brumas de los tiempos góticos no parecian tan lejanas. Ofrecian incluso hospedaje nominal a Lutero y a Calvino (Ibidem, pag. 881), asi nuevamente mixturados con "políticos".

26 Ibidem, pag. 891. 
Nuñez de Castro, comenzó con Witiza, aunque se consumara con Rodrigo. La explicación residía en no haber atendido debidamente que la Monarquía Española se había sfundado... más sobre la piedra firme de la fe, Pedro, que sobre las Columnas del valor, o sobre las bases de la Policía... ${ }^{27}$,

También la Corona Gótica, como podemos intuir, encerraba toda una reflexión acerca de los fundamentos de conservación y decadencia de imperios. Ya respondía en su concepción a presupuestos de matriz más castellana, pero que infundían el proyecto de significación más general de la misma Monarquía Católica. Nótese que se había comenzado por sugerir reflexión en un sentido más declaradamente de historia para concluir, en efecto, por religión. Las posibilidades de una percepción de lo particular, del propio tiempo con un valor más o menos autónomo se perdían de resultas de la propia operación de equiparación entre religión y conservación ${ }^{28}$. Como manifestación extrema, la posibilidad que en aquel sentido de aprehensión de lo particular pudiera haber ofrecido la fortuna, con su buena dosis de secularización, ya entraba declaradamente en el campo de quienes resultaban combatidos. Eran estas, se nos decía, formas de razonar no "cristianas", remitidas sin género de dudas a tribulaciones de "machiavellistae», con lo que ahora sabemos que ello significa. "No hay más Fortuna que Dios" habría titulado Calderón de la Barca a un conocido auto sacramental ${ }^{29}$. Todo guardaba su sentido.

La religión así, no sólo vínculo de la "sociedad", sino sostén de su propia conservación. O precisamente, por ser lo uno, era lo otro. Se trataba, como se nos decía, de la «basa», el «fundamento", firme soporte del "edificio" de la República, metáforas que acercaban a supuestos de leyes fundamentales que continentalmente ya se habian conseguido afir-

27 Nuñez De Castro, A., Corona Ghotica, Castellana y Austriaca. Segunda Parte compuesta de algunos originales que quedaron de D. Diego de Saavedra Faxardo, y continuada por... coronista de su Magestad... Madrid 1671, fol. I. La obra ya estaba compuesta en 24 de octubre de 1670 , fecha de aprobación más antigua.

${ }_{28}$ Vid. sobre estas cuestiones y por todos, Pocock, J. G. A., The Machiavellian Moment. Florentine Political Thought and the Atlantic Republican Tradition. Princeton 1975, págs. 3 y ss. y esp. págs. 31 y ss. Las discusiones con Julio A. Pardos sobre estos aspectos siempre han sido especialmente fructíferas para mi.

29 Calderón de la BARCA, P., No hay más fortuna que Dios, en Obras Completas, Valbuena Prat, A. Edt, Tomo III, Autos Sacramentales. Madrid (1959), 1967, págs. 611 y ss. Es obra posterior a 1652, quizá de 1653. 
mar ${ }^{30}$ pero que ya se distinguían precisamente por la propia fundamentalidad de la religión.

Los efectos de tal posición de la religión también se dejaban sentir en la percepción que de la relación entre Rey y súbditos se tenía. Destinado el monarca por oficio a la protección de la religión, el juego de dominios también se establecia en estas coordenadas. Es decir, la posibilidad de un Reino que gozase de un dominium directum y de un soberano que poseyera un dominium utile, con toda la derivación libertaria ${ }^{31}$ que de ello se pudiera desprender institucionalmente, desaparecería. "Dominio útil» lo tenía el monarca, pero la relación ya discurría hacia arriba, por cuanto el directo era poseído por Dios. Sufría así con ello la posibilidad de conformar relación contractual entre Rey y Reino. O cuando menos concebirla en los mismos términos que caracterizaban a una "Libertäre Verfassung" de presencia más europea. No era desconocimiento ${ }^{32}$. Se trataba de percepciones distintas. En estas condiciones, resultaba difícil habilitar un espacio propio para la «política». No se distinguía entre economía y política. Ya nos lo señalaba Francisco Enríquez que, no se olvide, ofrecía soluciones de conservación:

"La conservación de la Monarquía Católica depende de que su Príncipe, no tanto es Monarca Político, quanto padre económico" sin renunciar a aclarar lo que de por si ya resultaba bastante claro: "Todos los que tratan materias Políticas, assientan por principio cierto que para ser qual deve el govierno civil de un Monarca, ha de ser tan uno con el económico, que sólo se distinga de aquél en el número de los a quien govierna..." ${ }^{33}$.

30 Para planteamiento general sobre Leyes Fundamentales, por todos, MOHNAUPT, H., “Die Lehre von der 'Lex Fundamentalis' und die Hausgesetzgebung europäischen Dynastien", en KuNISCH, J. (edt.), Der dynastische Fürstenstaat. Zur Bedeutung von Sukzessionsordnungen für die Entstehung des frühmodernen Staates. Berlín 1982, págs. 3 y ss.

${ }^{31}$ Sobre estos conceptos, vid. BARUDIO, G., Absolutismus. Zerstörung der clibertären Verfassung». Studien zur "Karolinischen Eingewalt» in Schweden zswischen 1680 und 1683. Wiesbaden 1976, passim. Del mismo, La época del Absolutismo y la llustración, 1648-1779. Barcelona (1981), 1986, passim.

${ }_{32}$ Véase la consideración de SAAVEDRA en sus Locuras, cit. pág. 1.213:

«Luciano. También intenta probar (el autor francés de Cataluña francesa) que Barcelona fue conquistada por Carlomagno y que desde entonces quedó feudataria a Francia, para mostrar con esto que fue justa la rebelión, volviendo a su directo señor».

«Mercurio. En esta proposición se envuelven grandes designios, porque no es solo para escusar la rebelión, sino también para tener prevenida con tiempo la justificación del rompimiento de los fueros... para establecer un dominio absolutamente soberano; porque siendo los Reyes de Francia señores directos y no habiendo alguno de ellos confirmado ni jurado sus fueros... no estarán obligados a su observancia".

Ya se trataba también de territorios con fueros, no se olvide.

${ }_{33}$ Enriquez, F. Conservación, cit. Segunda Parte, Cap. XXVIII, fol. 48. 
La "comunicación» cabía. Cabía la directamente proporcional a los esquemas de comprensión del mundo que se poseían. Se trataba de una transposición a este propio campo de relación meramente autidoral ${ }^{34}$. La comunicación se fundaba en "amor", en "caritas». De una caridad transcental nos hablaba en esta no menos trascendental década Nieremberg ${ }^{35}$, quien no dejó de contraer anteriores compromisos de más explícita participación «antimaquiavelista». $Y$ también de libertad podía tratarse, pero la que entraba en esta concepción. El mismo Nieremberg nos volvía a aleccionar: «No hay mayor libertad, que de aquel que no quiere sino 10 que Dios quiere» ${ }^{36}$. Que al final todo girase en torno a virtudes, que los expedientes de gobierno que se pudiesen ofrecer al Monarca acabasen sustanciándose en la busqueda de virtudes cristianas e individuales, también formaba parte del orden de las cosas. "Genero de libertad es servir al sabio, como de cautiverio mandar al necio" ${ }^{37}$.

Que el concepto mismo de paz quedase con ello netamente confesionalizado también extrañará menos. Una paz que se entiende como «efecto de la religión" que entonces se decía. Paz, al menos en su dimensión general, inseparable de religión. No había espacio para acuerdos "politicos» en materia tan delicada. "Ay (sic) paz del mundo, y paz de Dios" ya nos advertía Quevedo, de forma que «tan apetecible es la paz, que siendo tan detestable la guerra, se debe hazer por adquirir paz en la religión y en la conciencia, y en la libertad justificada de la patria» ${ }^{38}$. Eran expedientes que imponía la percepción confesional. El amor y la caritas, no obstaculizaban en absoluto la implícita concepción de dominio que se escondían detrás de comprensiones del tipo. La "Pax Austriaca" era ciertamente poco pacifica en este sentido ${ }^{39}$. Tanto menos con un proyecto

34 Vid. Clavero, B., Antidora, cit. passim. para estas cuestiones.

35 NieremberG, J. E., Corona Virtuosa y Virtud Coronada, en que se proponen los frutos de la Virtud de un príncipe, juntamente con los heroicos exemplos de Virtudes de los Emperadores de la Casa de Austria, y Reyes de España. Madrid 1643. LA censura más antigua es de 5 de julio de 1642, en Madrid.

36 NiefemberG, J. E., "Centurias de Dictámenes Estoicos" contenido en su Corona Virtuosa. Desde pág. 313 se incluyen estas "Centurias de Dictámenes" que se agrupan en Reales, Morales y Estoicos. Aquí, Decada IX, núm. 82.

37 Nieremberg, J. E., "Centurias de Dictámenes Estoicos", cit. Década IX, 82

38 Quevedo, F., Política de Dios, ed. cit. Segunda parte, Cap. X., pág. 199. La publicación, por vez primera, de esta Segunda Parte en 1655 precisamente cuando debido a los problemas dinásticos de la rama austriaca se producian acercamientos a la rama hispana, es bien significativa. No sería del todo extraño sospechar que el lector avisado del momento pudiese comprender que entre las paces del mundo pudiera ciertamente incluirse la de Westfalia, tanto más dado el tenor combativo de la propia composición quevediana.

39 Vid. a este respecto y precisamente tratando del supuesto pacifismo de Saavedra las consideraciones de Straub, Pax et Imperium, cit. págs. 46-47, en referencia polémica al trata- 
que pudiera acabar por configurar un ordenamiento de radio europeo radicalmente diverso de la Weltanschauung que regía en el seno de la Monarquía Católica.

Era el alma del príncipe Baltasar Carlos la que se lo advertía, en una de sus visitas desde el purgatorio, a Sor María Jesús de Agreda:

«Sor María, de mi muerte se vale Dios para enseñar la verdadera sabiduría y arte de gobernar cristianamente esta Monarquía...; porque la Casa de Austria ha sido elegida y señalada por Dios para especial amparo de la iglesia y que por su medio se dilate la santa fe del evangelio en el mundo. $Y$ por esto la mira su Majestad con especial amor" ${ }^{40}$.

Y ya sabemos que éste era, a todos los efectos, un mundo más de almas que de cuerpos ${ }^{41}$.

miento de Saavedra que realiza JOVER en su, por lo demás aún muy aprovechable, 1635. Historia de una polémica y semblanza de una generación. Madrid 1949, págs. 391 y ss. Y para esa misma identificación del proyecto subyacente a la idea de "pax austriaca" y sin perder la referencia a Saavedra, BARUdio, G., Der Teutsche Krieg, cit. pág. 39.

${ }_{40}$ "Revelaciones del alma del príncipe Baltasar Carlos a Sor María", insertadas en carta de Sor María de Ágreda al Rey de 12 de octubre de 1646, recogido en María Jesús de Ágreda, Correspondencia con Felipe IV. Religión y Razón de estado, (Introd. de Baranda, C.). Madrid 1991, págs. 111-112.

"1 Clavero, B., "Almas y Cuerpos. Sujetos del derecho en la Edad Moderna", en Studi in Memoria di Giovanni Tarello. Vol. I, Saggi Storici. Milán 1990, págs. 153 y ss. 